\title{
Study of the formation and decomposition processes of agglomerates during fixed bed combustion of polymeric materials
}

\author{
Igor Donskoy ${ }^{1, *}$, Aleksandr Kozlov $^{1}$, Maksim Penzik ${ }^{1}$ and Denis Svishchev ${ }^{1}$ \\ ${ }^{1}$ Melentiev Energy Systems Institute, SB RAS, 130 Lermontova st., Irkutsk, Russia
}

\begin{abstract}
There are a lot of problems related with thermal utilization of municipal solid waste, including the agglomeration of fuel particles, which occurs during combustion and gasification of waste for energy production. In order to investigate the features of the agglomeration processes, experiments were carried out on melting polyethylene granules in a mixture with ceramic particles. Using a mathematical model, the characteristics of agglomeration in a fixed bed heated with a hot gas are investigated.
\end{abstract}

\section{Introduction}

Municipal waste, as a rule, contains a large fraction of combustible components, but their combustion is often difficult due to high moisture content, compositional heterogeneity, and complex thermal behavior. Polymer materials in waste can melt, swell and agglomerate. Agglomeration leads to a decrease in the combustion efficiency, the formation of burnouts and clinkers. In a number of experimental works, the formation of agglomerates during combustion and gasification of biomass and char [1, 2], peat [3], and plastics [4] was investigated. In our works $[5,6]$, we discussed the limitations on the gasification process efficiency associated with the agglomeration of fuel particles.

In this work, using experimental and theoretical methods, we investigated some features of the formation and decomposition of polyethylene agglomerates in a mixture with inert material.

\section{Experimental section}

Samples of agglomerates were prepared in a laboratory setup (internal diameter $15 \mathrm{~cm}$, layer height $14 \mathrm{~cm}$ ). Mixtures of polyethylene granules and expanded clay particles (mass ratio $1: 1$, batch weight $600 \mathrm{~g}$, particle size about $5 \mathrm{~mm}$ ) were used. The experimental setup is shown in Fig. 1. The walls of the reactor are electrically heated to a temperature of $350-400^{\circ} \mathrm{C}$. To prevent ignition, argon is used as gas medium (flow rate is 2 $1 / \mathrm{min}$ ). In the process of heating, polyethylene melts and fills the porous space, as a result of which the bed shrinks. Fig. 2 shows a typical agglomerate obtained by sintering polyethylene and expanded clay. In the above formulation, the size of the agglomerate is determined by the inner diameter of reactor, although a decrease in the polyethylene content is observed near the walls, which is associated with better conditions for melt flow.

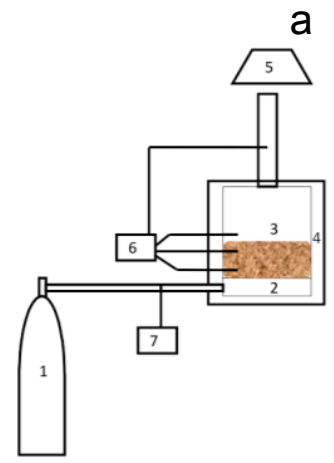

$1-$ gas tank

2 - heating zone under grate

$3-$ zone above bed

5 - ventpipe

6 - thermocouples

7 - pressure meter

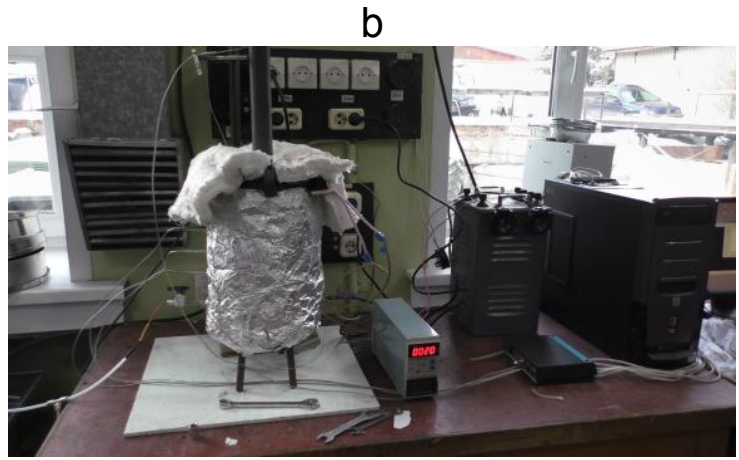

Fig. 1. Experimental setup scheme (a) and its exterior (b).

\footnotetext{
* Corresponding author: donskoy.chem $@$ mail.ru
} 


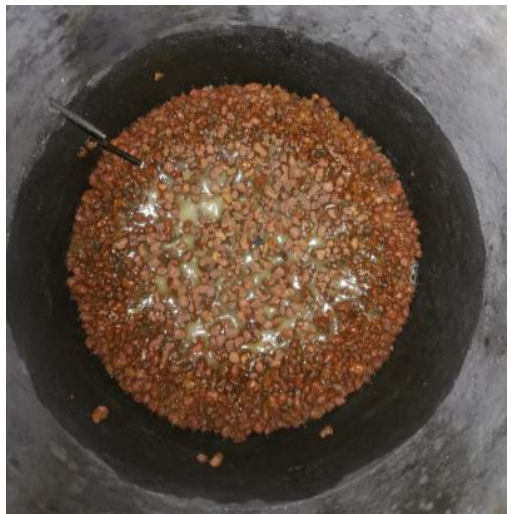

Fig. 2. Polyethylene-expanded clay agglomerate.

a

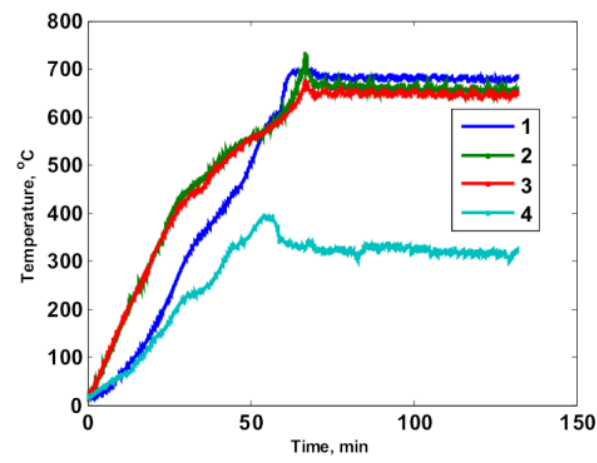

b

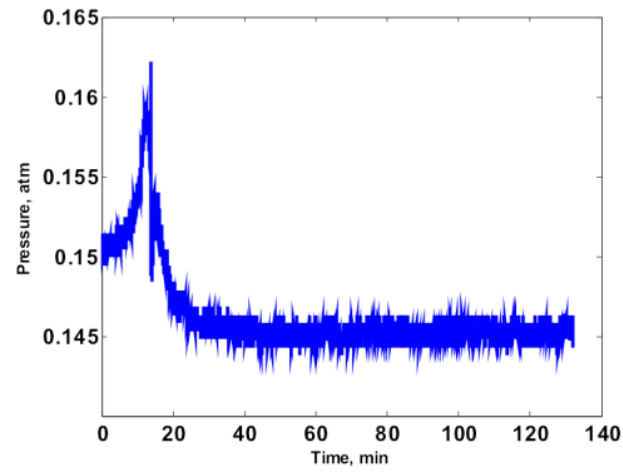

Fig. 3. Experimental results on agglomerate thermal decomposition: temperature in bed (a) and pressure drop between gas feed line and output (b).

After cooling, agglomerate was heated up to $700^{\circ} \mathrm{C}$ in air flow to clean reactor. The temperature curves are shown in Fig. 3a: thermocouples No. 1-3 are located in the bed, thermocouple No. 4 is at the gas outlet from the installation. The decomposition of the agglomerate occurs on its surface, and most of the mass does not participate in the reaction. Combustion occurs extremely slowly due to melting and deformation of the polyethylene surface layer. Therefore, despite the significant external heat input, the decomposition process takes more than hour to complete. Significant oscillations of temperature and pressure are observed during the process (Fig. $3 b$ ). Active combustion with a temperature rise in the wall temperature layer is observed only at the very late stage of agglomerate burnout. After the temperature and pressure had stabilized, the heating was turned off. Inspection of the contents showed that the decomposition of polyethylene was quite complete: expanded clay completely restored permeability, no polymer or soot residues on the walls and at the bottom were found after removing the material from the reactor.

\section{Theoretical section}

Numerical calculations of heating modes were carried out under the conditions of an experimental setup using the mathematical model from work [7] (similar models were used in works [8,9]). The following assumptions are made: the heat and mass transfer equations are twodimensional; gas filtration occurs according to Darcy's law; the effect of gravitational convection is negligible; uniform initial distribution of the polymer mass over the bed; decomposition of polyethylene is a single stage chemical reaction, the effective kinetic coefficients of the decomposition reaction are taken from [10]. Heating is carried out due to the heated gas, which is supplied to the particle bed at a constant pressure drop $(10 \mathrm{kPa})$. The initial temperature of the bed is $27^{\circ} \mathrm{C}$, the heating gas temperature rises from bed temperature to $327^{\circ} \mathrm{C}$ with different heating rates. When heated to the melting point $\left(200^{\circ} \mathrm{C}\right)$, the polyethylene melts and fills the porous space, as a result of which the permeability decreases by several orders of magnitude. The effective cross section of the bed decreases and the gas flow rate decreases sharply. In fig. 3 shows the change in the gas flow rate through the upper boundary of the bed at different heating rates.

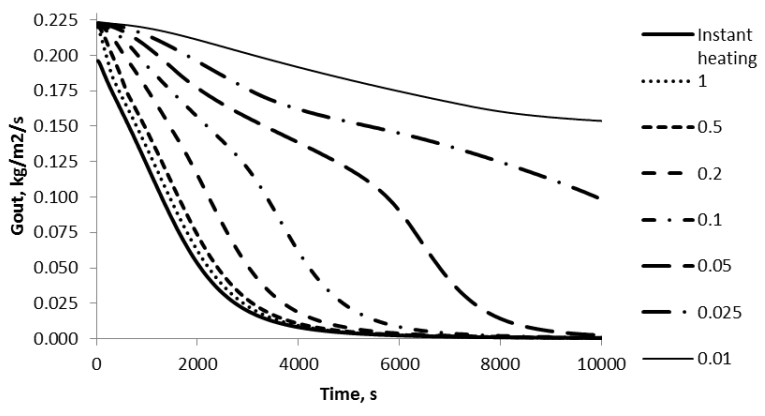

Fig. 3. Change in the mass flow rate of gas through the bed at a constant pressure drop (the numbers in the legend are the values of heating rate, $\mathrm{K} / \mathrm{s}$ ).

It can be seen from fig. 3 that with rapid gas heating (up to $0.5 \mathrm{~K} / \mathrm{s}$ ), the gas flow rate almost linearly decreases with time at the initial stage, after which the decrease in flow rate slows down. In this case, the lower part of the bed heats up quickly, the molten polymer forms a clinker, after which the bed is heated due to the thermal conductivity of the material.

With a further decrease in the heating rate, two stages of gas flow rate change are observed: the first stage with a slow decrease and the second stage, at which the flow rate decrease is close to exponential. The stage of a slow decrease in flow rate is apparently associated with the temperature dependence of the gas viscosity and density 
on temperature. After reaching the melting point of the polymer, the bed permeability drops sharply. Fig. 4 shows the dependence of the solid polyethylene fraction in the reactor on the heating time. Melting of about 15$20 \%$ polyethylene in the lower part of the reactor is sufficient to block the bed. With a decrease in the heating rate, the required fraction of molten polymer decreases: with slow heating, melting occurs in a larger volume of the reaction zone, therefore, the decrease in permeability becomes more uniform.

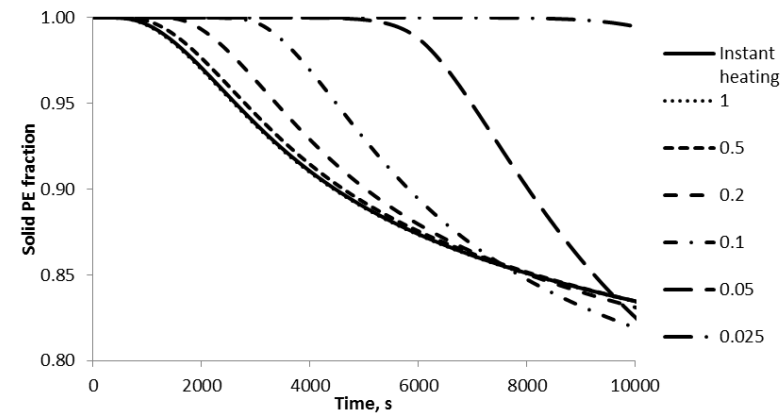

Fig. 4. Overall unmelted polyethylene fraction during bed heating (the numbers in the legend are the values of heating rate, $\mathrm{K} / \mathrm{s})$.

\section{Conclusion}

In this work, a study of the agglomeration of fixed bed consisting of polyethylene granules and inert material particles (expanded clay) was carried out. Samples of agglomerates were obtained, and their oxidative thermal decomposition was carried out. The features of clinker formation during polyethylene melting were investigated using a mathematical model. It is shown that with an increase in the gas heating rate, agglomeration in the lower part of the bed accelerates; therefore, to block the fixed bed, melting of a smaller fraction of the polymer is required.

This work was supported by Russian Fund for Basic Research (project number 19-08-00744) and was carried out using equipment of the multi-access scientific centre "High Temperature Circuit".

\section{References}

1. E. Madadian, in Gasification of Low-Grade Feedstock (InTech, Rjieka, 2018). DOI: 10.5772/intechopen.77119

2. M.V. Salganskaya, S.V. Glazov, E.A. Salganskii, A.F. Zholudev, Russ. J. Phys. Chem. B. 455 (2010). DOI: $10.1134 / \mathrm{S} 1990793110060096$

3. M.V. Tsvetkov, I.V. Zyukin, V.M. Freiman, M.V. Salganskaya, Y.Y. Tsvetkova, Russ. J. Appl. Chem. 901706 (2017). DOI: 10.1134/S1070427217100226

4. E. Madadian, C. Crowe, M. Lefsrud, J. Clean. Prod. 164137 (2017). DOI: 10.1016/j.jclepro.2017.06.070

5. I.G. Donskoi, Solid Fuel Chem. 52121 (2018). DOI: $10.3103 / \mathrm{S} 0361521918020027$
6. I.G. Donskoy, Bull. Tomsk Polytech. Univ. 330(2) 7 (2019). DOI: 10.18799/24131830/2019/2/89

7. I.G. Donskoy, Comp. tech. 25(2) 22 2020. DOI: 10.25743/ICT.2020.25.2.003

8. N.A. Lutsenko, Combust. Theor. Model. 22359 (2018). DOI: 10.1080/13647830.2017.1406617

9. N.A. Lutsenko, S.S. Fetsov, Int. J. Comp. Meth. 16 1950010 (2019). DOI: $10.1142 / \mathrm{S} 0219876219500105$

10. H. Bockhorn, A. Hornung, U. Hornung, D. Schawaller, J. Analyt. Appl. Pyrolysis 4893 (1999) DOI: 10.1016/S0165-2370(98)00131-4 